\title{
Collaborative Course Development: A New Model for Improved Student Outcomes
}

\author{
K. Damon Aiken, Timothy C. Heinze, Matthew L. Meuter, \\ and Kenneth J. Chapman
}

\begin{abstract}
This research proposes and tests the concept of collaborative course development (CCD) - a pedagogy in which students are actively involved in course design, empowered to make decisions about class structure, and free to make choices in assignments. Over a period of three academic terms, researchers taught experimental course sections utilizing CCD methods (i.e., employing various pedagogical techniques including syllabus building, "flex-tures," free-choice assignments, and exam writing), as well as control sections utilizing traditionally structured classroom techniques (i.e., professor-developed syllabi, structured lectures, forced-choice assignments, and professor-written exams). Results indicate that CCD classes yield significantly higher levels of student engagement, perceived learning, satisfaction, and ratings of professors. These main effects are consistent between and within professors. Interestingly, the positive effects associated with CCD teaching techniques are also consistent for students with high and low levels of two control variables (the preference for consistency and the separateness-connectedness self-schema).
\end{abstract}

\section{References available upon request.}

K.D. Aiken $(\bowtie) \bullet$ T.C. Heinze $\bullet$ M.L. Meuter $\bullet$ K.J. Chapman

California State University Chico, Chico, CA, USA

e-mail: kaiken@csuchico.edu; tcheinze@csuchico.edu; mmeuter@csuchico.edu;

kchapman@csuchico.edu 